\title{
The impact of rest breaks on subjective fatigue in physicians of the General Hospital of Vienna
}

\author{
Gerhard Blasche (ID) Anna Arlinghaus · Richard Crevenna
}

Received: 21 June 2021 / Accepted: 1 September 2021 / Published online: 6 October 2021

(C) The Author(s) 2021

\begin{abstract}
Summary
Aims Medical doctors are affected by high levels of occupational burnout. Work organization such as sufficient rest breaks can decrease stress and fatigue; however, rest breaks are often skipped under high workload and time pressure. The present study sought to investigate the effect of self-determined rest breaks on acute and daily levels of fatigue in physicians of the General Hospital of Vienna.

Methods Rest breaks and fatigue were recorded throughout day shifts over a time span of 4 weeks with a mobile assessment device. A total of 12 physicians of a university clinic participated in the study. Data were analyzed using generalized estimating equations. Results Analyses were based on a total of 115 workdays including 93 rest breaks and 800 fatigue assessments. Physicians took an average of 0.81 rest breaks per day. Fatigue was lower in the $30 \mathrm{~min}$ after the break than in the hour before the break; however, the number of rest breaks did not affect the increase of fatigue during shifts.

Conclusion Self-determined rest breaks were effective in reducing acute fatigue in hospital physicians during work. The failure to find an effect on the increase of work-related fatigue may be due to the infrequency of rest breaks in hospital physicians.
\end{abstract}

\section{G. Blasche $(\square)$}

Center for Public Health, Department of

Environmental Health, Medical University of Vienna, Kinderspitalgasse 15, 1090 Vienna, Austria

gerhard.blasche@meduniwien.ac.at

A. Arlinghaus

XIMES GmbH, Vienna, Austria

\section{R. Crevenna}

Department of Physical Medicine, Rehabilitation and

Occupational Medicine, Medical University of

Vienna/General Hospital of Vienna, Vienna, Austria
Keywords Subjective fatigue - Work Breaks . Burnout $\cdot$ Hospital physicians $\cdot$ Day shift

\section{Introduction}

Physicians are faced with high levels of burnout, a syndrome primarily based on emotional exhaustion (i.e. mental and motivational fatigue) and depersonalization (i.e. a negative attitude towards patients and work) [1]. Studies have found that the prevalence of burnout in physicians significantly exceeds that of the general public [2] and has increased in the last decade in various countries [3,4]. High levels of burnout also have been found in Austrian physicians [5], levels being comparable, albeit slightly lower, to those found in an international meta-analysis [6]. Consequences of physician burnout are severe, including an increased risk of patient safety, poorer quality of care, reduced patient satisfaction, lower productivity and lower levels of physician health [1, 7-9]. Several factors have been identified to contribute to burnout in physicians, including inefficient work processes, excessive workload, bad organizational climate and family responsibilities $[1,10]$.

Based on this situation recently described as "global crisis of physician burnout" by the Lancet [11], efforts to reduce burnout in physicians have been undertaken. Interventions aimed at the physician (e.g. stress management) and interventions aimed at the organization (e.g. focusing workload, work schedule or communication) are effective in reducing burnout, although those addressing the organization alleviate burnout to a greater degree [12, 13]. One measure potentially reducing burnout are rest breaks. Rest breaks can be seen as determined both by organizational as well as by individual factors [14, 15]. It can be assumed that rest breaks prevent the build-up of acute fatigue and thus reduce the risk of exhaustion on the 
long run, despite the fact that fatigue and burnout are overlapping, but not identical conditions [16, 17]. Rest breaks have been shown to reduce subjective fatigue $[18,19]$, improve performance and work engagement $[20,21]$ and reduce occupational injuries and physical complaints [22, 23]. For nurses, rest breaks are acknowledged to be important to sustain health and well-being [14]; however, despite some studies on the positive effect of rest breaks on surgeons during surgery $[23,24]$, rest breaks have not been studied in medical doctors to the best of our knowledge, which is surprising considering the elevated levels of burnout in this group of health professionals.

In the present study, the effect of rest breaks on fatigue was investigated in physicians of a University Clinic of the General Hospital of Vienna during day shifts. The present study utilized a design with high ecological validity, assessing self-determined rest breaks and fatigue throughout the workday over a time span of 4 weeks. For this purpose, a mobile device with minimal impact on working routine was used. We assumed that (hypothesis 1) subjective fatigue would be lower after a rest break than prior to a rest break, (hypothesis 2) subjective fatigue would increase over the workday, and (hypothesis 3 ) that the increase of fatigue over a working day would be negatively related with the number of rest breaks taken during that day.

\section{Material and methods}

\section{Study participants}

Study participants were 12 physicians (5 females, 7 males, mean age $=38.6$ years, SD 7.2 years) of the Department of Physical Medicine, Rehabilitation and Occupational Medicine of the General Hospital of Vienna working more than $35 \mathrm{~h}$ per week. Study participants only worked day shifts. Study participants were recruited by contacting all 17 department physicians via email and inviting them to participate in a study on the effect of rest breaks on fatigue. Information regarding the study was provided during a meeting. All study participants provided written informed consent.

\section{Design and procedure}

Study participants received a mobile device (XIMES corp. Vienna, Austria) [25] for recording rest breaks as well as fatigue during workdays for a time span of 4 weeks. Individuals recorded the start and end of individually paced rest breaks defined as temporary interruptions of work for the means of recovery with a duration of at least $3 \mathrm{~min}$. No restrictions were placed on the number, time and duration of rest breaks, which were fully at the individual's discretion. In addition, individuals were prompted roughly every $90 \mathrm{~min}$ by a vibration of the device to record their present level of fatigue with a single item measure. Fatigue was also assessed at the beginning and end of each workday. Every fatigue assessment was recorded with a time stamp. The beginning and end of workdays were determined by activating and deactivating the device by the study participant. The assessment took place from 5 to 27 November 2019. The study was approved by the ethics board of the Medical University of Vienna (EK Nr. 2020/2018).

\section{Variables}

The dependent variable was acute fatigue assessed with the single item measure "How much in need of recovery do you feel at the present moment?". This item was chosen from the items of the fatigue subscale from a standardized German well-being questionnaire [26] on the basis of previous diary research $[27,28]$ as it showed the highest levels of change sensitivity. Answers were coded on a worded numeric rating scale with the descriptors $1=$ "not at all" ("gar nicht"), 2= "hardly" ("kaum"), 3= "slightly" ("leicht"), 4 = "averagely" ("mittel”), $5=$ "fairly" ("ziemlich"), 6= "very" ("sehr") and 7= "extraordinarily" ("außerordentlich"). The fatigue measure showed an acceptable distribution $(\mathrm{m}=3.9, \mathrm{SD}=1.8$, skewness $=0.08$, kurtosis $=-0.79$, range $=1-7$ ). The independent variables were the number of rest breaks per day (rest break frequency), the time of day as well as the relative time between rest breaks and fatigue assessments. Additional variables were the number of assessment days and workdays per individual, the beginning and end of workday and the duration of workdays.

\section{Data analysis}

The original dataset included a total of 172 observation days with a total of 986 fatigue assessments and 118 rest breaks. Of these, 5 days were excluded because they did not contain any fatigue assessments. An additional 39 days with less than 5 daily fatigue assessments were excluded to provide sufficient data for estimating daily means and changes of fatigue. In addition, 13 short workdays, i.e. workdays starting after 9:00 $\mathrm{h}$ and/or ending before 14:00 h, were excluded, leaving a total of 115 days for the final analyses, including a total of 800 fatigue assessments. Of the rest breaks 8 were excluded because of durations shorter than $3 \mathrm{~min}$, leaving a total of 93 rest breaks. In a first step, secondary variables such as the number and duration of workdays per person, the number of rest breaks per day and the duration of rest breaks were determined from the primary variables using Excel formulas. Data were then analyzed with SPSS 26 (IBM Corp.) using the procedure generalized estimating equations. Calculations were based on a linear model using a robust estimator adjusted by the number of nonredundant parameters and an independent 
working correlation matrix. A subject variable was entered in every model. To evaluate the acute effect of rest breaks, levels of fatigue 0-30, 31-60 and 61-90 min following the rest break were compared to levels of fatigue in the hour preceding the rest break (entered as categorical variable). To control for time of day effects, the hour of day was added as covariate (entered as continuous variable). To evaluate the effect of the number of rest breaks per day on the level and change of fatigue on a given day, fatigue was predicted by a modified rest break frequency variable as described below as well as the time of day and an interactive term to evaluate the change of fatigue as a consequence of rest breaks (entered as categorical variables). Effects sizes (Cohens d) were calculated with the estimated means and the standard errors transformed to standard deviations.

The original rest break frequency variable (i.e. number of rest breaks per day) was unsuitable for analyses as some categories contained 5 or fewer entries, which can be considered insufficient for analysis. In addition, rest breaks were quite unequally distributed between study participants, the average number of rest breaks per day varying between 0 and 3 rest breaks per participant and the total number of days with rest breaks varying between $0 \%$ (2 individuals) and $100 \%$ (4 individuals). Therefore, a new rest break variable (rest break variation) was determined to be able to observe the intra-individual effect of the variation of rest breaks encompassing two categories. This variable compared the minimum number of rest breaks per day (which was 0 for 8 individuals, 1 for 3 individuals and 2 for 1 individual, coded as " 0 ") with all other days with a larger number of rest breaks (coded as "1"). In effect, the variable rest break variation compared days with fewer or no rest breaks ( $j$, where $0 \leq j \leq 2$, coded as 0 ) with days with one or more additional rest breaks $(j+k$, where $1 \leq k \leq 3$, coded as $1)$.

\section{Results}

The average number of observation days (i.e. workdays) per person was 9.6 days (SD 4.5 days, range 2-16), the number of fatigue assessments was 66.7 assessments (SD 33.3 assessments, range 15-120). The average duration of workdays was $8.2 \mathrm{~h}$ (SD $0.91 \mathrm{~h})$. Individuals started their workday at 7:46 (SD 0:31) and ended it at 15:55 (SD=0:47). An average of 0.81 rest breaks (SD 1.0) per day was observed, with a minimum of 0 and a maximum of 5 breaks. The majority of breaks $(41 \%)$ were taken at lunchtime (12:00-13:59h), $22 \%$ in the mid-morning between 10:00-11:59h, $14 \%$ in the early morning between $7: 00-8: 59 \mathrm{~h}$ and $23 \%$ in the afternoon after 13:00 h. The average duration of rest breaks was $23.0 \mathrm{~min}$ (SD $14.1 \mathrm{~min}$ ), varying between 3 and $48 \mathrm{~min}, 46$ breaks (49\%) were longer than $20 \mathrm{~min}$ and thus can be considered as lunch breaks.

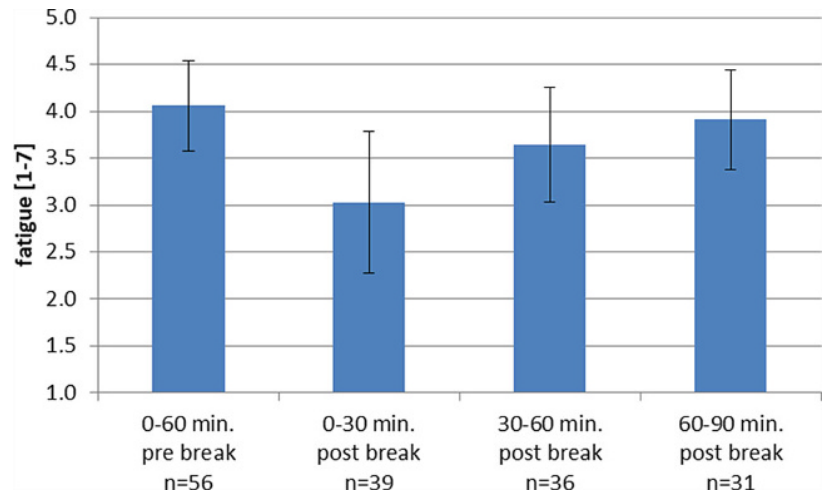

Fig. 1 Acute effect of rest breaks on subjective fatigue; estimated means (corrected for hour of day) and $95 \%$ confidence intervals are displayed; $n$ is the number of observations

The acute effect of self-determined rest breaks is illustrated in Fig. 1. Fatigue was lower in the $30 \mathrm{~min}$ after the break than in the hour before the break $(\mathrm{B}=-1.03, \mathrm{SE}=0.21, p<0.001)$, with a medium effect size of $d=0.49$. A near significant difference to the pre-break level was found for fatigue $31-60 \mathrm{~min}$ after the break $(B=-0.42, \mathrm{SE}=0.23, p=0.076 ; \mathrm{d}=0.23)$, whereas $60-90 \mathrm{~min}$ after the break levels of fatigue did not differ from the pre-break level $(\mathrm{B}=-0.15, \mathrm{SE}=0.33$, $p=0.65$ ). This result supports hypothesis 1 . The hour of day as control variable was positively related to fatigue $(\mathrm{B}=0.23, \mathrm{SE}=0.10, p=0.017)$. The goodness of fit of this analysis was QIC (Quasi Likelihood under Independence Model Criterion) $=327$.

The effect of the time of day and rest breaks on fatigue during workdays is illustrated in Fig. 2. Fatigue increased significantly during a workday $(p<0.001$; $\mathrm{B}$ (midday: $10-13 \mathrm{~h}$ ) $=0.94, \mathrm{SE}=0.18, p<0.001$; $\mathrm{B}$ (afternoon: $14-18 \mathrm{~h})=1.67, \mathrm{SE}=0.25, p<0.001$; reference cathegory: morning (6-9h)), thus supporting hypothesis 2. The overall effect of rest break variation (i.e. days with the minimum number of rest breaks per person versus days with more than the mini-

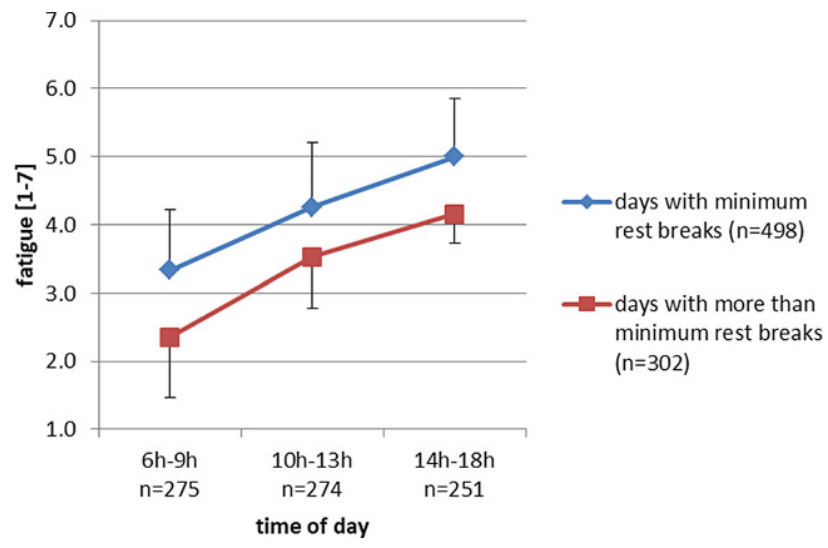

Fig. 2 Effect of rest break variation on subjective fatigue during workdays; estimated means (corrected for hour of day) and $95 \%$ confidence intervals are displayed; $n$ is the number of observations 
mum number of rest breaks) on overall fatigue during workdays was significant $(p=0.033$; $\mathrm{B}$ (additional breaks) $=-0.98, \mathrm{SE}=0.51$; reference cathegory: minimum rest breaks). Fatigue generally was lower on days where individuals took more breaks; however, rest break variation did not affect the change of fatigue during a workday ( $p=0.27$; $\mathrm{B}$ (additional breaks $\times$ midday $=0.24, \mathrm{SE}=0.19 ; \mathrm{B}$ (additional breaks $\times$ afternoon) $=0.13$, $\mathrm{SE}=0.35$; reference cathegory: additional breaks $\times$ morning). Thus, hypothesis 3 was not supported. The goodness of fit of this analysis was $\mathrm{QIC}=2121$.

\section{Discussion}

Medical doctors are faced with high levels of burnout, a syndrome characterized among others by exhaustion. A measure known to alleviate fatigue and thus potentially preventing burnout are rest breaks, the temporary interruptions of work for the means of recovery. The present study sought to investigate the effect of self-determined rest breaks on subject fatigue in physicians working at a university clinic.

Self-chosen rest breaks were associated with an immediate decrease in fatigue in the $30 \mathrm{~min}$ following the break as compared to the $60 \mathrm{~min}$ before the break, indicating that rest breaks were effective in reducing fatigue during routine work. Fatigue increased in the next 30min following the break, with a level still marginally below pre-break levels. An hour after the break fatigue was non-significantly different from prebreak levels. These effects are comparable to those of other studies showing that rest breaks acutely reduce fatigue in natural work settings [18, 19]; however, the present study is the first to suggest that the effect of rest breaks on subjective fatigue dissipates in the 90 min following the break, when work is resumed.

In the present study, subjective fatigue increased over the workday, indicating that work was indeed tiring. An increase in fatigue during real or simulated work in various occupations also has been found in several other studies [29-31]; however, in contrast to these studies, where fatigue increased predominantly in the afternoon, morning and afternoon increases in fatigue were of similar magnitude in the present study, possibly reflecting high morning levels of workload. An alternative explanation for the observed morning increase in fatigue is that individuals showed low levels of burnout and/or high sleep quality [29, 31]; however, this latter explanation is unlikely keeping in mind the high levels of burnout reported for physicians [2].

Contrary to expectation, rest breaks did not have an effect on the change of fatigue during the workday. The time course of fatigue was similar on days individuals took one or more rest breaks compared to days when individuals took fewer or no rest breaks. This result differs from the results of a study on driving examiners showing that taking rest breaks at reg- ular intervals during the workday was associated with lower levels of post-work fatigue compared to not taking any rest breaks [32]. Similarly, it is in contrast to a study showing that nurses who were more inclined to take rest breaks had lower levels of fatigue at the end of their work shift [15]. A reason for the failure to find positive results on the change of fatigue may be the generally low number of breaks observed in the present study. In contrast to the average of 0.9 breaks per day observed here, other studies report an average number of rest breaks between 2.5 [18] and 2.9 [15] per day. Despite the large differences in the taking of rest breaks between individuals in the present study, even the number of rest breaks in those taking more breaks may have been insufficient to affect the time course of fatigue. Another reason may lie in the timing of rest breaks. It has been shown that breaks taken in the afternoon have a greater impact on fatigue than those taken in the morning [21]. In the present study, however, only few breaks were taken in the afternoon, thus potentially limiting their effect on fatigue.

Despite the failure to find an effect of breaks on the change of fatigue over the workday, there was an effect on the mean levels of daily fatigue. Individuals taking more rest breaks had lower levels of fatigue during the workday. This is in line with the results of a study on hospital physicians showing that the adherence to designated breaks was associated with lower levels of emotional exhaustion [33]; however, as fatigue tends to accumulate over a workday as indicated, one would expect rest breaks to have a greater impact on fatigue when fatigue levels are higher. Possibly, the effect of rest breaks on mean levels of fatigue is a result of interindividual differences in study participants, for example regarding gender [34] or work engagement [35]. Future studies will have to assess these individual differences to be able to clarify this issue.

The participants of the present study took considerably fewer rest breaks than observed in studies conducted with predominantly administrative employees $[15,18]$. These differences cannot be accounted for by different assessment methods, as all studies assessed breaks using diaries or experience sampling. Thus, it is reasonable to assume that they are associated with professional and/or occupational characteristics. For example, the majority of surgeons appraise intraoperative breaks negatively, despite their documented benefits for both the surgeon and the patient [36]. Although taking breaks during a surgical procedure is a special case, it may also reflect doctors' attitude towards work breaks in general, suggesting that physicians are more reluctant to take breaks than members of other professions. In addition, occupational characteristics in healthcare may impede the taking of breaks due to higher levels of occupational demands and lower levels of control [37].

It is worth noting that the number of days individuals recorded data differed strongly between indi- 
viduals. Although these differences in study participation may be due to factors not associated with the study (sick leave, vacation, other work constraints), they may also reflect differences in study adherence; however, due to the small number of study participants it was not possible to evaluate if these potential differences in study adherence affected outcomes in the present study by for example the omission to record rest breaks.

The strength of the present study is the use of a mobile assessment system, which allowed us to track rest breaks as well as subjective fatigue during a workday with objectively assessed clock times. Limitations of the present study are the relatively small number of study participants and observed rest breaks, reducing overall variance and limiting the power of the study. To achieve a greater statistical power and to enable a more finely tuned analysis, for example evaluating the effect of a broader range of daily rest breaks or differences between morning and afternoon breaks, the study would need to be replicated with a larger number of study participants. A second related limitation are the large interindividual differences in observation days, leading to an unequal contribution of study participants to the overall results.

To conclude, rest breaks acutely reduce fatigue in hospital physicians during day shifts. Taking more rest breaks was also associated with lower levels of overall fatigue during dayshifts; however, rest breaks did not dampen the increase of fatigue during shifts. Possibly, the failure to counteract increases in fatigue is due to the infrequency of breaks observed in medical doctors. Thus, although the results suggest that rest breaks reduce fatigue on a short-term basis, future studies with larger sample sizes will have to ascertain whether rest breaks can counteract the increase in fatigue during a work shift and thus provide a means for preventing professional burnout in physicians.

Acknowledgements We would like to thank Ingwald Strasser for his efforts in supporting the present study as employee representative within the Medical University of Vienna and its various review boards.

Funding Open access funding provided by Medical University of Vienna.

\section{Declarations}

Conflict of interest G. Blasche, A. Arlinghaus and R. Crevenna declare that they have no competing interests.

Ethical standards The study was approved by the ethics board of the Medical University of Vienna (EK Nr. 2020/2018). Informed consent was obtained from all individual participants included in the study.

Open Access This article is licensed under a Creative Commons Attribution 4.0 International License, which permits use, sharing, adaptation, distribution and reproduction in any medium or format, as long as you give appropriate credit to the original author(s) and the source, provide a link to the Creative Commons licence, and indicate if changes were made. The images or other third party material in this article are included in the article's Creative Commons licence, unless indicated otherwise in a credit line to the material. If material is not included in the article's Creative Commons licence and your intended use is not permitted by statutory regulation or exceeds the permitted use, you will need to obtain permission directly from the copyright holder. To view a copy of this licence, visit http://creativecommons.org/licenses/by/4.0/.

\section{References}

1. West CP, Dyrbye LN, Shanafelt TD. Physician burnout: contributors, consequences and solutions. J Intern Med. 2018;283(6):516-29.

2. Shanafelt TD, Boone S, Tan L, Dyrbye LN, Sotile W, Satele D, et al. Burnout and satisfaction with work-life balance among US physicians relative to the general US population. Arch Intern Med. 2012;172(18):1377-85.

3. Richter A, Kostova P, Baur X, Wegner R. Less work: more burnout? A comparison of working conditions and the risk of burnout by German physicians before and after the implementation of the EU working time directive. Int Arch Occup Environ Health. 2014;87(2):205-15.

4. Shanafelt TD, Hasan O, Dyrbye LN, Sinsky C, Satele D, Sloan J, et al. Changes in burnout and satisfaction with work-life balance in physicians and the general US working population between 2011 and 2014. Mayo Clin Proc. 2015;90(12):1600-13.

5. Schmid T, Troy C-D. Arbeitsbedingungen und Arbeitsbelastungen in den Gesundheitsberufen in Wien und Niederösterreich sowie bei angestellten ÄrztInnen in NÖ. Wien: Sozioökonomische Forschungsstelle; 2010.

6. Rotenstein LS, Torre M, Ramos MA, Rosales RC, Guille C, Sen S, et al. Prevalence of burnout among physicians a systematic review. JAMA. 2018;320(11):1131-50.

7. PanagiotiM, GeraghtyK, JohnsonJ,ZhouA, PanagopoulouE, Chew-Graham C, et al. Association between physician burnout and patient safety, professionalism, and patient satisfaction: a systematic review and meta-analysis. JAMA Intern Med. 2018;178(10):1317-30.

8. Dewa CS, Loong D, Bonato S, Thanh NX, Jacobs P. How does burnout affect physician productivity? A systematic literature review. BMC Health Serv Res. 2014;14(1):325. https://doi.org/10.1186/1472-6963-14-325.

9. Dewa CS, Loong D, Bonato S, Trojanowski L. The relationship between physician burnout and quality of healthcare in terms of safety and acceptability: a systematic review. BMJOpen. 2017;7(6):2016-15141.

10. Balch CM, Shanafelt TD, Dyrbye L, Sloan JA, Russell TR, Bechamps GJ, et al. Surgeon distress as calibrated by hours worked and nights on call. J Am Coll Surg. 2010;211(5):609-19.

11. The L. Physician burnout: a global crisis. Lancet. 2019;394(10193):93.

12. WestCP, Dyrbye LN, Erwin PJ, ShanafeltTD. Interventions to prevent and reduce physician burnout: a systematic review and meta-analysis. Lancet. 2016;388(10057):2272-81.

13. PanagiotiM,PanagopoulouE, BowerP,Lewith G, Kontopantelis E, Chew-Graham C, et al. Controlled interventions to reduceburnoutin physicians a systematic reviewandmetaanalysis. JAMAIntern Med. 2017;177(2):195-205.

14. Wendsche J, Ghadiri A, Bengsch A, Wegge J. Antecedents and outcomes of nurses' rest break organization: a scoping review. Int J Nurs Stud. 2017;75:65-80.

15. Blasche G, Pasalic S, Bauböck VM, Haluza D, Schoberberger R. Effects of rest-break intention on rest-break 
frequency and work-related fatigue. Hum Factors. 2017;59(2):289-98.

16. Demerouti E, Bakker AB, Nachreiner F, Schaufeli WB. The job demands-resources model of burnout. J Appl Psychol. 2001;86(3):499-512.

17. Leone SS, Huibers MJ, Knottnerus JA, Kant IJ. Similarities, overlap and differences between burnout and prolonged fatiguein the working population. Qjm. 2007;100(10):617-27.

18. Zacher H, Brailsford HA, Parker SL. Micro-breaks matter: a diary study on the effects of energy management strategies on occupational well-being. J Vocat Behav. 2014;85(3):287-97.

19. Blasche G, Szabo B, Wagner-Menghin M, Ekmekcioglu C, Gollner E. Comparison of rest-break interventions during a mentally demanding task. Stress Health. 2018;34(5):629-38

20. Wendsche J, Lohmann-Haislah A, Wegge J. The impact of supplementary short rest breaks on task performance: a meta-analysis. sozialpolitikch. 2016; https://doi.org/10. 18753/2297-8224-75.

21. Kühnel J,Zacher H, de Bloom J, BledowR. Take a break! Benefits of sleep and short breaks for daily work engagement. Eur JWork Organ Psy. 2017;26(4):481-91.

22. Fischer D, Lombardi DA, Folkard S, Willetts J, Christiani DC. Updating the "risk index": a systematic review and metaanalysis of occupational injuries and work schedule characteristics. Chronobiol Int. 2017;34(10):1423-38.

23. Park AE, Zahiri HR, Hallbeck MS, Augenstein V, Sutton $\mathrm{E}, \mathrm{Yu} \mathrm{D}$, et al. Intraoperative "micro breaks" with targeted stretching enhance surgeon physical function and mental focus a multicenter cohort study. Ann Surg. 2017;265(2):340-6.

24. Engelmann C, Schneider M, Kirschbaum C, Grote G, Dingemann J, Schoof S, et al. Effects of intraoperative breaks on mental and somatic operator fatigue: a randomized clinical trial. Surg Endosc. 2011;25(4):1245-50.

25. Ximes. DiesmarteTätigkeits- und Belastungsanalyse. 2021. https://www.ximes.com/page/smarte-tatigkeitsanalyse. Accessed 20 May 2021

26. Nitsch J. Die Eigenzustandsskala (EZ-Skala) - Ein Verfahren zur hierarchisch-mehrdimensionalen Befindlichkeitsskalierung [Personal state scale-A hierarchicalmultidimensional procedure to assess well-being]. In: Nitsch JR, Udris I, editors. Beanspruchung im Sport. Bad Hombug v.d.H:Limpert; 1976. pp. 81-102.
27. Blasche G, Bauböck VM, Haluza D. Work-related self-assessed fatigue and recovery among nurses. Int Arch Occup Environ Health. 2017;90(2):197-205.

28. BlascheG,ZilicJ,Frischenschlager O. Task-relatedincreases in fatigue predict recovery time after academic stress. J Occup Health. 2016;58(1):89-95.

29. Hülsheger UR. From dawn till dusk: shedding light on the recovery process by investigating daily change patterns in fatigue. JAppl Psychol. 2016;101(6):905-14.

30. Geiger-Brown J, Rogers VE, Trinkoff AM, Kane RL, Bausell RB, Scharf SM. Sleep, sleepiness, fatigue, and performance of 12-hour-shift nurses. Chronobiol Int. 2012;29(2):211-9.

31. Veldhuizen IJT, Gaillard AWK, de Vries J. The influence of mental fatigue on facial EMG activity during a simulated workday. Biol Psychol. 2003;63(1):59-78.

32. Meijman TF. Mental fatigue and the efficiency of information processing in relation to work times. Int J Ind Ergon. 1997;20(1):31-8.

33. Tanner G, Bamberg E, Kersten M, Nienhaus A, Kozak A. The relationship between working time and ill health differences between full-time and part-time workers. Zeitschrift für Arbeits- und Organisationspsychologie. 2017;61(4):181-96.

34. Akerstedt T, Fredlund P, Gillberg M, Jansson B. Work load and work hours in relation to disturbed sleep and fatigue in a large representative sample. J Psychosom Res. 2002;53(1):585-8.

35. Salanova M, Del Líbano M, Llorens S, Schaufeli WB. Engaged, workaholic, burned-out or just 9-to-5? Toward a typology of employee well-being. Stress Health. 2014;30(1):71-81.

36. Engelmann C, Schneider M, Grote G, Kirschbaum C, Dingemann J, Osthaus A, et al. Work breaks during minimally invasive surgery in children: patient benefits and surgeon's perceptions. Eur J Pediatr Surg. 2012;22(6):439-44.

37. Lohmann-Haislah A, Wendsche J, Schulz A, Schöllgen I, Pinzon LCE. Einflussfaktoren und Folgen des Ausfalls gesetzlicher Ruhepausen bei Pflegekräften in Deutschland. ZArbeitswiss. 2019;73(4):418-38.

Publisher's Note Springer Nature remains neutral with regard to jurisdictional claims in published maps and institutional affiliations. 